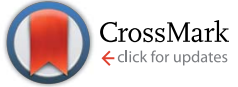

Cite this: RSC Adv., 2017, 7, 9316

Received 11th November 2016 Accepted 6th January 2017

DOI: 10.1039/c6ra26646k

www.rsc.org/advances

\section{Rapid electrochemical synthesis of HKUST-1 on indium tin oxide}

\author{
Li-Long Jiang, ${ }^{b}$ Xiangzhou Zeng, ${ }^{a}$ Mengkai Li, ${ }^{a}$ Man-Qing Wang, ${ }^{a}$ Tong-Yu Su, ${ }^{a}$ \\ Xiao-Chun Tian ${ }^{c}$ and Jing Tang ${ }^{\star a}$
}

We synthesized a HKUST-1 metal-organic framework (MOF) on indium tin oxide (ITO) using an electrodeposited $\mathrm{Cu}$ film. The electrodeposited $\mathrm{Cu} / \mathrm{ITO}$ was used as a source of $\mathrm{Cu}$ ions, which were linked with benzene-1,3,5-tricarboxylic acid on the ITO surface to form HKUST-1. Synthesized HKUST-1/ ITO was characterized by X-ray diffraction (XRD), Raman spectroscopy and scanning electron microscopy (SEM), which showed that the morphology of the HKUST-1 framework was nearly octahedral. Our results also revealed that the growth of HKUST-1 depended on the potential and synthesis time used. This method can be applied to fabricate ordered patterns of HKUST-1 on ITO substrates, offering a new way to grow MOFs on many other kinds of conductive substrates.

\section{Introduction}

In the last 20 years, many researchers have focused on developing metal-organic frameworks (MOFs), which are a new class of porous material that consist of $1 \mathrm{D}, 2 \mathrm{D}$, or 3D networks of metal ions linked together by organic bridging ligands. ${ }^{1,2}$ HKUST-1 (CuBTC, BTC = benzene-1,3,5-tricarboxylic acid) is an interesting MOF with a 3D network containing large pores with square cross sections $(9 \times 9 \AA)$, desirable for gas separation and purification. ${ }^{3}$ Studies have also been performed on its electrochemical synthesis, behavior and applications. ${ }^{4-6}$ Traditional means of synthesizing HKUST-1 include room temperature synthesis, conventional electric (CE) heating, microwave (MW) heating, electrochemistry (EC), and mechanochemistry (MC).

Another interesting synthesis method is that proposed by Müller et al: direct anodic dissolution of metal in an electrolyte containing an organic linker. $\mathrm{Cu}$ electrodes have been commonly used for this methods to synthetize HKUST-1., ${ }^{7,8}$ In the electrochemical synthesis process, the electrolyte composition, current density, and applied potential have been shown to influence the morphology of the resultant HKUST-1. ${ }^{9}$ However, MOF films should be able to be coated on a variety of substrates for different

${ }^{a}$ Key Laboratory of Analysis and Detection Technology for Food Safety, Ministry of Education, College of Chemistry and Chemical Engineering, Fuzhou University, Fuzhou, 350108, Fujian Province, P. R. China. E-mail: jingtang@fzu.edu.cn; Fax: +86 59122866165; Tel: +8659122866165

${ }^{b}$ National Engineering Research Center for Chemical Fertilizer Catalyst at Fuzhou University College of Chemistry and Chemical Engineering, Fuzhou University, Fuzhou, 350108, Fujian Province, P. R. China

'Department of Chemistry, College of Chemistry and Chemical Engineering, Xiamen University, Xiamen, 361005, Fujian Province, P. R. China. E-mail: tianxiaochun@ hotmail.com applications, because integrated, patterned, or sensitive devices are often not fabricated on pure $\mathrm{Cu}$ substrates. ${ }^{10}$

Herein, we introduce a novel process to synthesize HKUST-1 on a conductive indium tin oxide (ITO) substrate which consists two electrochemical steps. Since the $\mathrm{Cu}$ ions are produced near the $\mathrm{Cu} / \mathrm{ITO}$ substrate, the HKUST-1 crystals can be directly formed on the ITO surface. The as synthesized HKUST-1 was characterized by X-ray diffraction (XRD), Raman spectroscopy and scanning electron microscopy (SEM). This method was applied to fabricate ordered patterns of HKUST-1 on ITO substrates and could be used as a new way to grow MOFs on various conductive substrates.

\section{Experimental}

We used analytical-grade reagents and ultrapure water throughout our experiments. Tetrabutyl ammonium perchlorate (TBAP) $(\geq 99.0 \%)$ used for electrochemical analysis was purchased from Sigma-Aldrich, and BTC (98\%) was obtained from Aladdin. ITO (1.1 mm thickness, resistivity $<30 \Omega \mathrm{cm}^{-1}$ ) obtained from Xiamen Ito Photoelectricity Ind Co., Ltd. (Xiamen, China) was used as the electrode and to support the HKUST-1.

We performed all electrochemical experiments with a standard three-electrode cell on a CHI614D or a CHI842B electrochemistry workstation (Shanghai ChenhuaAppatatus Corporation, China). A saturated calomel electrode (SCE) and a Pt slice were used as the reference electrode and the auxiliary electrode, respectively. The sample solutions were purged with high-purity nitrogen for at least ten minutes to remove oxygen prior to the experiments. The ITO (working area of $\sim 1 \times 1 \mathrm{~cm}$ ) was ultrasonically cleaned with acetone, alcohol, and ultrapure water successively. 
The process to synthesize HKUST-1 on the ITO substrate using two electrochemical steps. The first step is to electrodeposit a thin film of $\mathrm{Cu}$ on ITO using a solution of $5 \mathrm{mmol} \mathrm{L}^{-1}$ $\mathrm{CuSO}_{4}+0.1 \mathrm{~mol} \mathrm{~L}^{-1} \mathrm{~K}_{2} \mathrm{SO}_{4}$ for $500 \mathrm{~s}$. The second step is forming the HKUST-1 by anodically dissolving the $\mathrm{Cu}$ film in a $3: 1 \mathrm{v} / \mathrm{v}$ solution of EtOH and $\mathrm{H}_{2} \mathrm{O}$ containing $25 \mathrm{mmol} \mathrm{L}^{-1}$ BTC as a linking agent and $50 \mathrm{mmol} \mathrm{L}{ }^{-1}$ TBAP as a supporting electrolyte, and the anodically dissolving time is $100 \mathrm{~s}$.

The morphology and microstructure of the synthesized $\mathrm{Cu} /$ ITO and HKUST-1/ITO were characterized by SEM (NOVA NANO SEM 230) and Raman spectroscopy (inVia Renishaw, UK). The XRD patterns of the $\mathrm{Cu} / \mathrm{ITO}$ over the range of $10-90^{\circ}$ were obtained with a Philips X'Pert Pro MPD (Holland) powder diffraction system using Co $\mathrm{K} \alpha$ radiation with a $2 \theta$ step size of $0.02^{\circ}$. XRD measurements were also taken for $5-20^{\circ}$ using a Rigaku diffractometer with an accelerating voltage of $40 \mathrm{kV}$, $\mathrm{Cu} \mathrm{K} \alpha$ radiation, a $2 \theta / \theta$ step size of $0.01^{\circ}$, and a step width of $0.5^{\circ}$.

\section{Results and discussion}

The process to synthesize HKUST-1 on the ITO substrate is using two electrochemical steps. As Fig. 1(a) shows, the first step of this method is to electrodeposit a thin film of $\mathrm{Cu}$ on ITO. The second step is forming the HKUST-1 by anodically dissolving the $\mathrm{Cu}$ film. A thin layer of $\mathrm{Cu} / \mathrm{ITO}$ was synthesized by electrodeposition and used as a source for synthesizing HKUST-1/ ITO. The $\mathrm{Cu} / \mathrm{ITO}$ substrate was prepared by electrodepositing $\mathrm{Cu}$ at a constant potential of $-0.8 \mathrm{~V}$ for $500 \mathrm{~s}$. Fig. 1(b) shows the electrochemical behavior of ITO in this solution. The reduction of $\mathrm{Cu}^{2+}$ onto the ITO begins at $0 \mathrm{~V}$ and reaches a peak at $-0.3 \mathrm{~V}$, limited by diffusion. The obtained $\mathrm{Cu} / \mathrm{ITO}$ was used as a substrate to synthesize HKUST-1/ITO. As Fig. 1(c) shows, when the potential scans in the positive direction relative to the open circuit potential $(0.01 \mathrm{~V})$, the oxidation current increases obviously and reaches a peak at $1.2 \mathrm{~V}$. This behavior indicates that the electrodeposited $\mathrm{Cu}$ oxidizes to $\mathrm{Cu}^{2+}$ and then reacts with BTC in the electrolyte to generate HKUST-1 on the ITO surface, as shown in the first curve of Fig. 1(c). However, HKUST-1 on ITO is not electrochemically stable when the potential is scanned in the negative direction (curve 2). The current generated by the reduction of $\mathrm{Cu}^{2+}$ in HKUST-1 increases to a maximum current at $-0.6 \mathrm{~V}$. When the potential scans in the positive direction again (curve 3), the Cu redissolves and quickly links with the BTC to redeposit as HKUST-1. The reduction current is smaller in curve 4 than in curve 2 because of redissolved $\mathrm{Cu}^{2+}$ ions used for the HKUST-1 formation and some $\mathrm{Cu}^{2+}$ diffusing into the bulk solution till all $\mathrm{Cu}$ will be dissolved. It seems that the amount of HKUST-1 decreases after many potential cycles between $-1.0 \mathrm{~V}$ and $1.5 \mathrm{~V}$ vs. SCE. Therefore, we chose to synthesize HKUST-1 using a fixed $1.5 \mathrm{~V}$ potential.

Fig. 2(a) shows the morphology of the electrodeposited $\mathrm{Cu}$ / ITO. The $\mathrm{Cu}$ film consist of uniformly dispersed $\mathrm{Cu}$ nanoparticles, which have an average diameter of $100 \mathrm{~nm}$. And Fig. 2(b) shows octahedral HKUST-1 formed on ITO after anodic dissolution of $\mathrm{Cu} / \mathrm{ITO}$ at $1.5 \mathrm{~V}$ for $100 \mathrm{~s}$. In this case, the size of a single HKUST-1 particle is ten times larger than the $\mathrm{Cu}$ nanoparticles. Fig. 2 (c) shows an XRD pattern $\left(2 \theta=25-80^{\circ}\right)$ of the $\mathrm{Cu} / \mathrm{ITO}$ and HKUST-1/ITO obtained in our experiment; the peaks with asterisks are those obtained from the ITO substrate. In Fig. 2(c), the XRD diffraction patterns of $\mathrm{Cu} / \mathrm{ITO}$ at $50.7^{\circ}$ and $59.3^{\circ}$ clearly correspond to the (111) and (200) lattice planes of $\mathrm{Cu}$, respectively. After HKUST-1/ITO forms, the peaks at $50.7^{\circ}$ and $59.3^{\circ}$ disappear. This result indicates that almost all of $\mathrm{Cu}$ was electro-oxidized under our optimized experimental conditions. Fig. 2(d) shows the diffraction pattern of HKUST-1 and that simulated by Chui et al. ${ }^{11}$ Our experimental result has an extremely intense diffraction peak at $11.6^{\circ}$, which corresponds
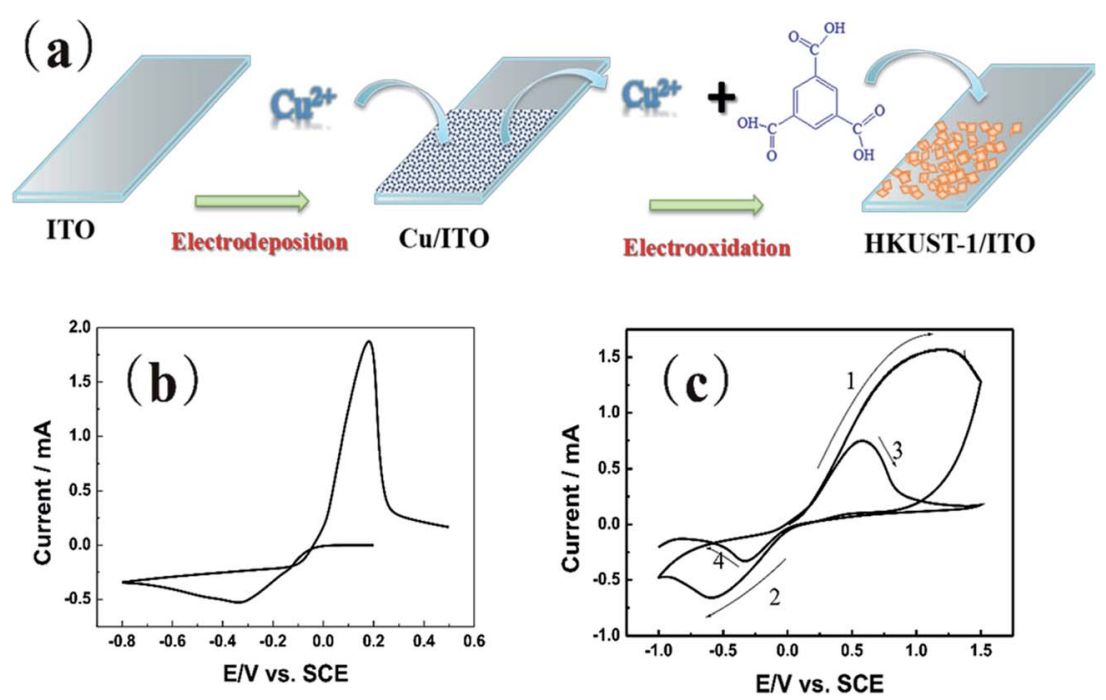

Fig. 1 (a) Schematic of the rapid synthesis of a HKUST-1 film on ITO using an electrodeposited Cu film as a source. (b) Cyclic voltammograms of ITO in a $5 \mathrm{mmol} \mathrm{L}^{-1} \mathrm{CuSO}_{4}$ electrolyte containing $0.1 \mathrm{~mol} \mathrm{~L}^{-1} \mathrm{~K}_{2} \mathrm{SO}_{4}$ as a supporting electrolyte. Scan rate: $50 \mathrm{mV} \mathrm{s}^{-1}$. (c) Cyclic voltammograms of $\mathrm{Cu} / \mathrm{ITO}$ in a solvent $\left(\mathrm{v}_{\mathrm{EtOH}} / \mathrm{v}_{\mathrm{H}_{2} \mathrm{O}}=3: 1\right)$ containing $25 \mathrm{mmol} \mathrm{L}{ }^{-1} \mathrm{BTC}$ as a linking agent and $50 \mathrm{mmol} \mathrm{L}^{-1}$ TBAP as a supporting electrolyte. Scan rate: $50 \mathrm{mV} \mathrm{s}^{-1}$. 

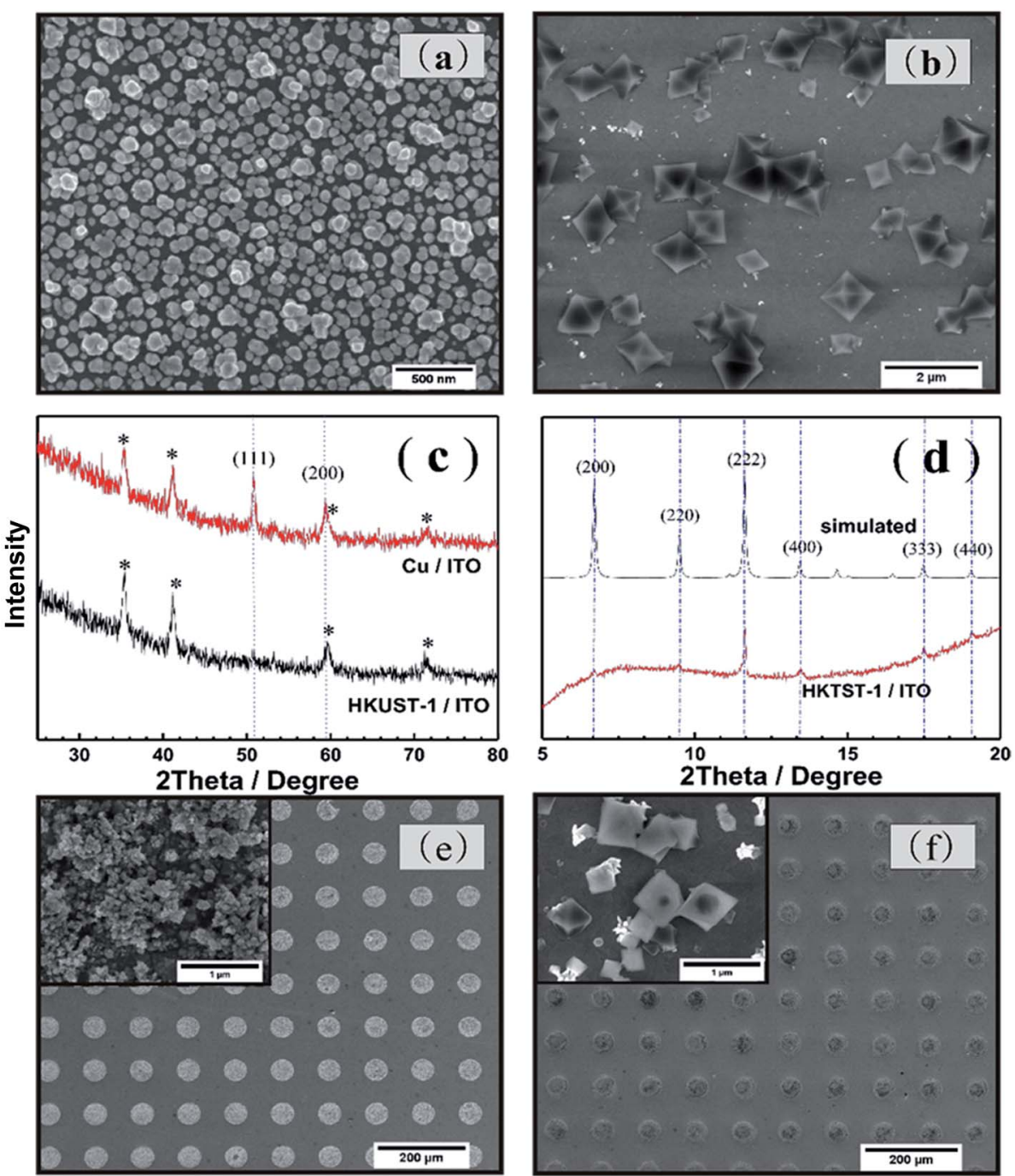

Fig. 2 SEM images of (a) Cu/ITO and (e) patterned Cu/ITO which electrochemical synthetized at a constant potential of $-0.8 \mathrm{~V}$ for $500 \mathrm{~s}$ in $5 \mathrm{mmol} \mathrm{L}^{-1} \mathrm{CuSO}_{4}+0.1 \mathrm{~mol} \mathrm{~L}^{-1} \mathrm{~K}_{2} \mathrm{SO}_{4}$. SEM images of (b) HKUST-1/ITO and (f) patterned HKUST-1/ITO obtained in a solvent ( $\mathrm{V}_{\mathrm{EtOH}} / \mathrm{V}_{\mathrm{H}} \mathrm{O}=3: 1$ ) $+25 \mathrm{mmol} \mathrm{L}^{-1} \mathrm{BTC}+50 \mathrm{mmol} \mathrm{L}^{-1}$ TBAP at $1.5 \mathrm{~V}$ for $100 \mathrm{~s}$. (c) XRD pattern of Cu/ITO and HKUST-1/ITO, $2 \theta=25-80^{\circ}$. (d) XRD pattern of HKUST$1 /$ ITO compared to its simulated pattern, $2 \theta=5-20^{\circ}$.

to the (222) lattice plane of HKUST-1, and another at $17.4^{\circ}$, which corresponds to the (333) lattice plane of HKUST-1. However, the other diffraction peaks of HKUST-1 at $6.7^{\circ}$, $13.4^{\circ}, 9.5^{\circ}$, and $18.0^{\circ}$ are very weak; these peaks correspond to the (200), (400), (220), (440) planes, respectively. Overall, the diffraction pattern of HKUST-1/ITO agrees well with the simulated pattern, these results confirm that we successfully synthesized HKUST-1 on ITO using an electrochemical method. Furthermore, our electrochemical method can fabricate patterned HKUST-1 on ITO substrates. We electrodeposited a circular pattern of $\mathrm{Cu}$ with a diameter of $50 \mu \mathrm{m}$ on ITO using an electrochemical wet stamping technique. ${ }^{\mathbf{1 2}}$ We observe HKUST-1 growth after maintaining a potential of $1.5 \mathrm{~V} v s$. SCE for $100 \mathrm{~s}$. The inset of Fig. 2(f) shows that the octahedral crystal of HKUST-1 replaces the original $\mathrm{Cu}$ nanoparticles, as shown in the inset of Fig. 2(e). Compared with other HKUST-1 patterning techniques, our method is simple, rapid, low cost, and can be used to pattern large areas.

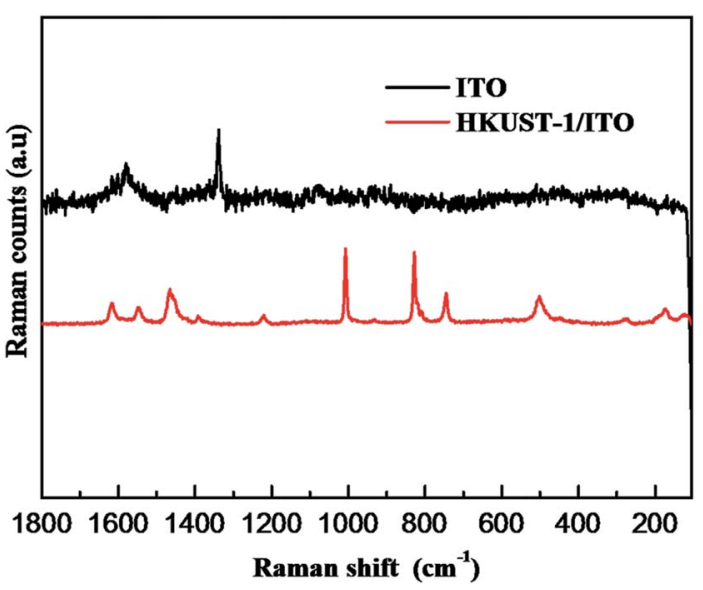

Fig. 3 Raman spectroscopy of ITO and HKUST-1/ITO. Laser wavelength: $532 \mathrm{~nm}$ laser power: 10\%. 

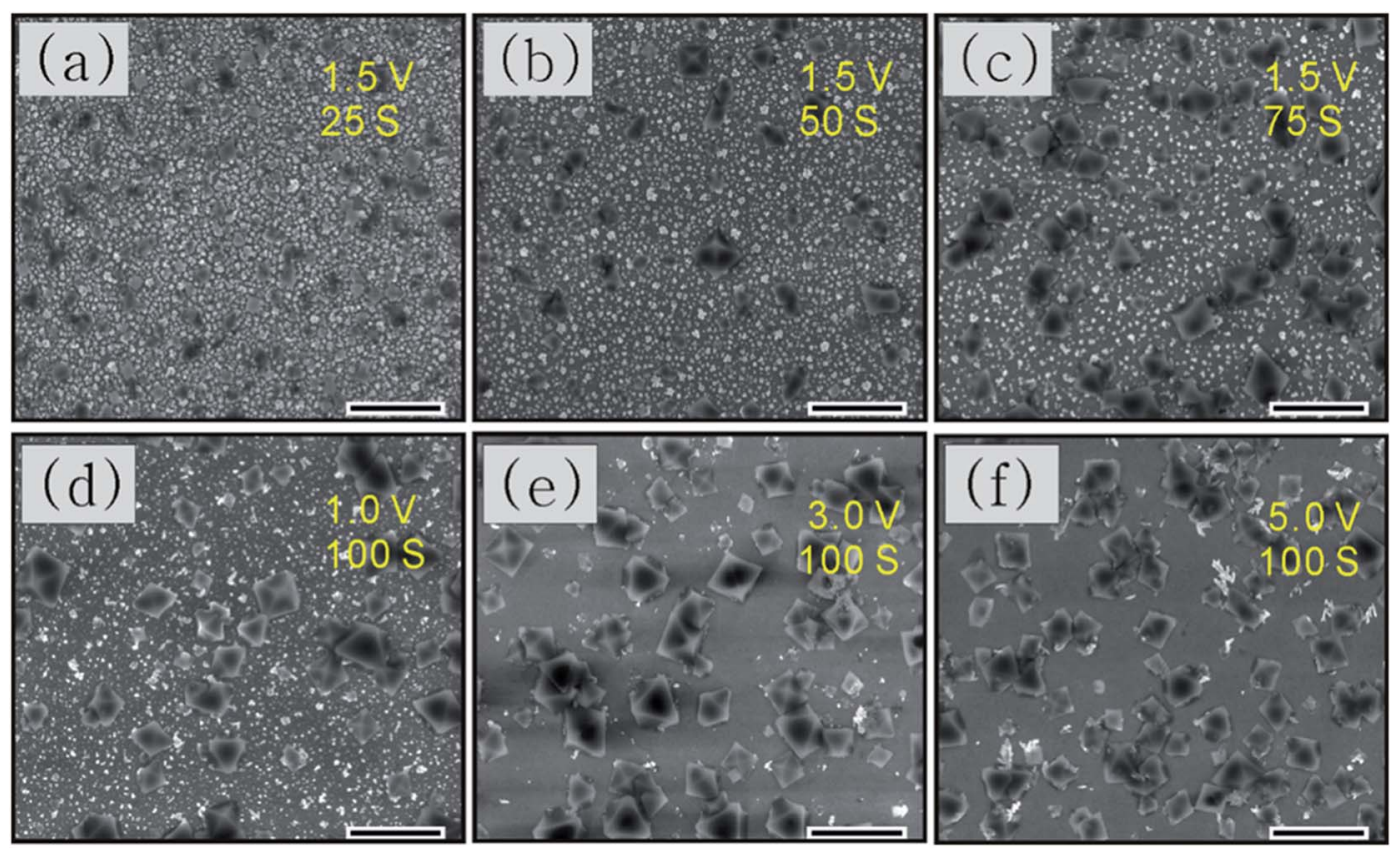

Fig. 4 SEM images of HKUST-1/ITO, formed by electro-oxidation of $\mathrm{Cu} / \mathrm{ITO}$ in a solvent $\left(\mathrm{v}_{\mathrm{EtOH}} / \mathrm{v}_{\mathrm{H}_{2} \mathrm{O}}=3: 1\right)$ containing $25 \mathrm{mmol} \mathrm{L}^{-1} \mathrm{BTC}$ as a linking agent and $50 \mathrm{mmol} \mathrm{L}^{-1}$ TBAP as a supporting electrolyte at $1.5 \mathrm{~V}$ for (a) $25 \mathrm{~s}$, (b) $50 \mathrm{~s}$, or (c) $75 \mathrm{~s}$, and at different potentials of (d) $1.0 \mathrm{~V}$, (e) $3.0 \mathrm{~V}$, or (f) $5.0 \mathrm{~V}$ for $100 \mathrm{~s}$. The scale bar is $2 \mu \mathrm{m}$ long.

In order to further indicate the synthesis of HKUST-1, Raman spectroscopy is used to obtain structural information on HKUST-1 (Fig. 3). Comparison with ITO, the spectrum of HKUST-1 is dominated by modes associated with the organic part of the MOF framework. For example, the bands at 1610 and $1006 \mathrm{~cm}^{-1}$ are associated with $\nu(\mathrm{C}=\mathrm{C})$ modes of the benzene ring; the peaks at 826 and $740 \mathrm{~cm}^{-1}$ are ascribed to out-of-plane ring $(\mathrm{C}-\mathrm{H})$ bending vibrations and to out-of-plane ring bending, respectively, while the doublet at 1550 and $1460 \mathrm{~cm}^{-1}$ is due to the $\nu_{\text {sym }}\left(\mathrm{C}-\mathrm{O}_{2}\right)$ and $\nu_{\mathrm{ym}}\left(\mathrm{C}-\mathrm{O}_{2}\right)$ units. $^{13}$

We used SEM to perform a preliminary study of the deposition time and potential used for synthesis. Fig. 4(a-c) shows the morphologies of the resultant crystals deposited with different times taken for anodic dissolution of $\mathrm{Cu}$ with a constant potential of $1.5 \mathrm{~V} v s$. SCE. For $25 \mathrm{~s}$, as shown in Fig. 4(a), very little $\mathrm{Cu}$ has dissolved and HKUST-1 particles sparsely cover the ITO surface. For longer anodization times such as $50 \mathrm{~s}$, small HKUST-1 crystals with discernible shapes begin appearing on the ITO, increasing the distribution density of HKUST-1. After $75 \mathrm{~s}$, the crystal morphology is clearly octahedral and most of the $\mathrm{Cu}$ film has dissolved. The potential used could also determine the final morphology of HKUST-1 on ITO; thus, it is important to study. In our method, we can control the concentration of $\mathrm{Cu}$ ions by monitoring the applied potential; a higher anodic potential corresponds to a higher concentration of $\mathrm{Cu}$ ions due to dissolution of the $\mathrm{Cu}$ film. Fig. 4(d-f) shows the final morphologies of samples deposited at different potentials for $100 \mathrm{~s}$. As Fig. 4(d) shows, when the oxidation potential is $1 \mathrm{~V}$, only a low concentration of $\mathrm{Cu}^{2+}$ is generated, and intergrowth of truncated octahedral crystals occurs. For $3 \mathrm{~V}$ as in Fig. 4(e), the intermediate concentration of $\mathrm{Cu}^{2+}$ leads to a well-defined octahedral HKUST-1. However, at $5 \mathrm{~V}$ as in Fig. 4(f), the very high concentration of $\mathrm{Cu}^{2+}$ results in more irregular crystals. Thus, formation kinetics can be tuned by adjusting the applied potential and the time of anodic dissolution of the $\mathrm{Cu}$ film.

\section{Conclusions}

We have successfully fabricated HKUST-1 on ITO using a twostep electrochemical synthesis: electro-deposition of $\mathrm{Cu}$ on ITO and then electro-oxidation of the Cu/ITO to HKUST-1/ITO. This method is simple, fast, mild, and environmentally friendly, and we believe that it will benefit research on electrochemical synthesis of other MOFs. More importantly, this approach allows us to coat patterned MOFs onto many other kinds of conductive substrates used in microelectronic devices.

\section{Acknowledgements}

The authors are grateful for financial support from the National Science Foundation of China (21573043, 21173048, 21073038). The authors would also like to acknowledge Professor ZhaoXiong Xie and Senior Engineer Yi-Wen Ye from Xiamen University for their help measuring the XRD spectra of HKUST1/ITO.

\section{References}

1 S. L. James, Metal-organic frameworks, Chem. Soc. Rev., 2003, 32, 276-288. 
2 H. C. Zhou, J. R. Long and O. M. Yaghi, Introduction to metal-organic frameworks, Chem. Rev., 2012, 112, 673-674.

3 J. R. Li, J. Sculley and H. C. Zhou, Metal-organic frameworks for separations, Chem. Rev., 2012, 112, 869-932.

4 R. Senthil Kumar, S. Senthil Kumar and M. Anbu Kulandainathan, Efficient electrosynthesis of highly active $\mathrm{Cu}_{3}$ (BTC) $)_{2}$-MOF and its catalytic application to chemical reduction, Microporous Mesoporous Mater., 2013, 168, 57-64.

5 R. Senthil Kumar, S. Senthil Kumar and M. Anbu Kulandainathan, Highly selective electrochemical reduction of carbon dioxide using $\mathrm{Cu}$ based metal organic framework as an electrocatalyst, Electrochem. Commun., 2012, 25, 70-73.

6 J. Mao, L. Yang, P. Yu, X. Wei and L. Mao, Electrocatalytic fourelectron reduction of oxygen with copper(II)-based metalorganic frameworks, Electrochem. Commun., 2012, 19, 29-31.

7 R. Ameloot, L. Stappers, J. Fransaer, L. Alaerts, B. F. Sels and D. E. De Vos, Patterned Growth of Metal-Organic Framework Coatings by Electrochemical Synthesis, Chem. Mater., 2009, 21, 2580-2582.

8 T. R. C. Van Assche, G. Desmet, R. Ameloot, D. E. De Vos, H. Terryn and J. F. M. Denayer, Electrochemical synthesis of thin HKUST-1 layers on copper mesh, Microporous Mesoporous Mater., 2012, 158, 209-213.

9 A. Martinez Joaristi, J. Juan-Alcañiz, P. Serra-Crespo, F. Kapteijn and J. Gascon, Electrochemical Synthesis of Some Archetypical $\mathrm{Zn}^{2+}, \mathrm{Cu}^{2+}$, and $\mathrm{Al}^{3+}$ Metal Organic Frameworks, Cryst. Growth Des., 2012, 12, 3489-3498.

10 L. E. Kreno, K. Leong, O. K. Farha, M. Allendorf, R. P. Van Duyne and J. T. Hupp, Metal-organic framework materials as chemical sensors, Chem. Rev., 2012, 112, 1105-1125.

11 S. S.-Y. Chui, S. M.-F. Lo, J. P. H. Charmant, A. G. Orpen and I. D. Williams, A Chemically Functionalizable Nanoporous Material $\left[\mathrm{Cu}_{3}(\mathrm{TMA})_{2}\left(\mathrm{H}_{2} \mathrm{O}\right)_{3}\right]_{n}$, Science, 1999, 283, 1148-1150.

12 J. Tang, J. L. Zhuang, L. Zhang, W. H. Wang and Z. W. Tian, Cu micropatterning on $\mathrm{n}-\mathrm{Si}(111)$ by selective electrochemical deposition using an agarose stamp, Electrochim. Acta, 2008, 53, 5628-5631.

13 C. Prestipino, L. Regli, J. G. Vitillo, F. Bonino, A. Damin, C. Lamberti, A. Zecchina, P. L. Solari, K. O. Kongshau and S. Bordiga, Local Structure of Framework Cu(II) in HKUST1 Metallorganic Framework Spectroscopic Characterization upon Activation and Interaction with Adsorbates, Chem. Mater., 2006, 18, 1337-1346. 